\title{
TGA/DTG/DSC investigation of thermal ageing effects on polyamide-imide enamel
}

\author{
Barbara Gornicka • Lech Gorecki
}

CCTA10 Special Issue

(C) The Author(s) 2010. This article is published with open access at Springerlink.com

\begin{abstract}
Thermoanalytical investigations TGA/DTG/ DSC of polyamide-imide enamel after thermal ageing have been presented. The lifetimes at $260,270,280,290,300{ }^{\circ} \mathrm{C}$ were determined. The thermograms of the enamels after attaining of their lifetimes much depend on the ageing temperature. The temperatures of $5 \%$ loss of mass that much increase after thermal ageing appear the most sensitive indicator of ageing rate. The residue of mass at $800{ }^{\circ} \mathrm{C}$ increases after ageing, even to $27 \%$, due to diffusion of copper ions from the conductor into enamel during annealing. The copper contents in aged coatings could be also an indicator of ageing rate.
\end{abstract}

Keywords Enamel - Thermal ageing - Thermoanalysis · Winding wire

\section{Introduction}

Evaluation of thermal endurance, one of the most essential properties of the electroinsulating materials, serves the purpose of revealing how prolonged exposure to elevated temperature produces irreversible degradation of materials properties [1-6]. Thermal ageing is an effect temperature influenced of chemical and physical reaction. The Arrhenius equation indicates a linear relationship between the logarithm of life time and the reciprocal absolute

B. Gornicka $(\bowtie) \cdot$ L. Gorecki

Division of Electrotechnology and Materials Science,

Electrotechnical Institute, M. Sklodowskiej-Curie 55/61,

50-369 Wroclaw, Poland

e-mail: gornicka@iel.wroc.pl temperature that is utilized in standard procedure for the thermal endurance characterization described in IEC 60216. According to this standard cyclic ageing at three or more constant temperatures are performed and the aged specimens are subjected to diagnostic procedures which may be non-destructive or destructive tests using specified properties. The evaluation of thermal endurance electroinsulating materials can be achieved either through conventional long-term tests, according to IEC 60216, or by using short-term procedures which are based on analytical techniques [5, 7-9]. Thermal analysis has been frequently used to study the overall thermal degradation kinetics of polymers [10-12]. For thermosetting polymers the elevated temperature will first cause acceleration of the completion of curing and improving its properties. Thermal degradation causes depolymerization, random chain scission, sidegroup elimination and oxidation [7-9]. The conventional model for thermal degradation is that of an autoxidation process.

In this project insulating enamel of winding wire was subjected to conventional cyclic thermal ageing according to IEC 60216 and IEC 60172 and thermoanalytical investigation of samples at various stages of thermal degradation were performed. Furthermore, the TG/DTG/DSC thermograms have been studied, due to determine, what parameters have been changed during ageing and could be also the indicators of the degree of thermal degradation.

\section{Experimental}

Material under testing was enamel of a polyamide-imideenamelled round copper wire (type IEC 60317-26). Polyamide-imides hold a positive synergy of properties from both polyamides and polyimides, such as high strength, 
melt processibility and exceptional high heat capability. Samples of enamelled wire in form of "twisted pairs" were cyclic aged, according to IEC 60172, at rather high temperatures: $260,270,280,290$ and $300{ }^{\circ} \mathrm{C}$. After each cycle an insulating coating was subjected to the proof test: $900 \mathrm{~V}$ applied over $2 \mathrm{~s}$. The sample can fail proof test because of the loss of the coating thickness and the decomposition of the enamel during ageing. At various exposure temperatures the lifetimes have been determined for the dielectric diagnostic criterion.

Moreover, the TGA/DTG/DSC thermoanalytical investigation of enamel at various stages of degradation was performed, using Mettler Toledo thermogravimetric analyzer TGA/DSC1. The parameters were the heating rate $10 \mathrm{~K} / \mathrm{min}$, temperature range from 23 to $800{ }^{\circ} \mathrm{C}$, sample mass $10 \mathrm{mg}$, air flow $50 \mathrm{~mL} / \mathrm{min}$.

There were determined thermograms TGA/DTG/DSC of the cyclic aged coatings that had attained their lifetimes

Table 1 Lifetimes of enamel at various exposure temperatures determined according to IEC 60172

\begin{tabular}{llc}
\hline No. & Ageing temperature $/{ }^{\circ} \mathrm{C}$ & Lifetime $/ \mathrm{h}$ \\
\hline 1 & 260 & 1128 \\
2 & 270 & 576 \\
3 & 280 & 336 \\
4 & 290 & 216 \\
5 & 300 & 108 \\
\hline
\end{tabular}

according to the standard. In addition, the continuous ageing at 280 and $290{ }^{\circ} \mathrm{C}$ was carried out and thermograms of the enamel after various periods of exposure were performed.

The temperatures used for the assessment of beginning of degradation, i.e. onset temperatures and $5 \%$ loss of mass temperatures, were read out from the mass loss rate curves TG. The maximum peak temperatures were determined from the DSC and DTG curves.

\section{Results and discussion}

The results of thermal endurance investigation, i.e. the times to reach the end-point criterion at each exposure temperature (lifetimes), are presented in Table 1.

Above data were plotted on a graph with the logarithm of times to end-point $t$ versus reciprocal of absolute temperature $T$. The obtained results followed Arrhenius rule and the dependence was linear.

The results of thermoanalytical investigations of the cyclic-aged samples that gained end-point are presented in Fig. 1. The TG thermogram of the unaged enamel shows two mass loss steps but the thermal ageing causes a decay of the first one. At the first stage of an ageing the additional crosslinking (curing) of enamel take places, later decomposition of amide bonds and at last imide bonds. Degradation process is accelerated in the presence of copper of wire conductor acting as a catalyst [9].
Fig. 1 The TG, DTG and DSC curves of samples that reach their lifetimes at various ageing temperatures

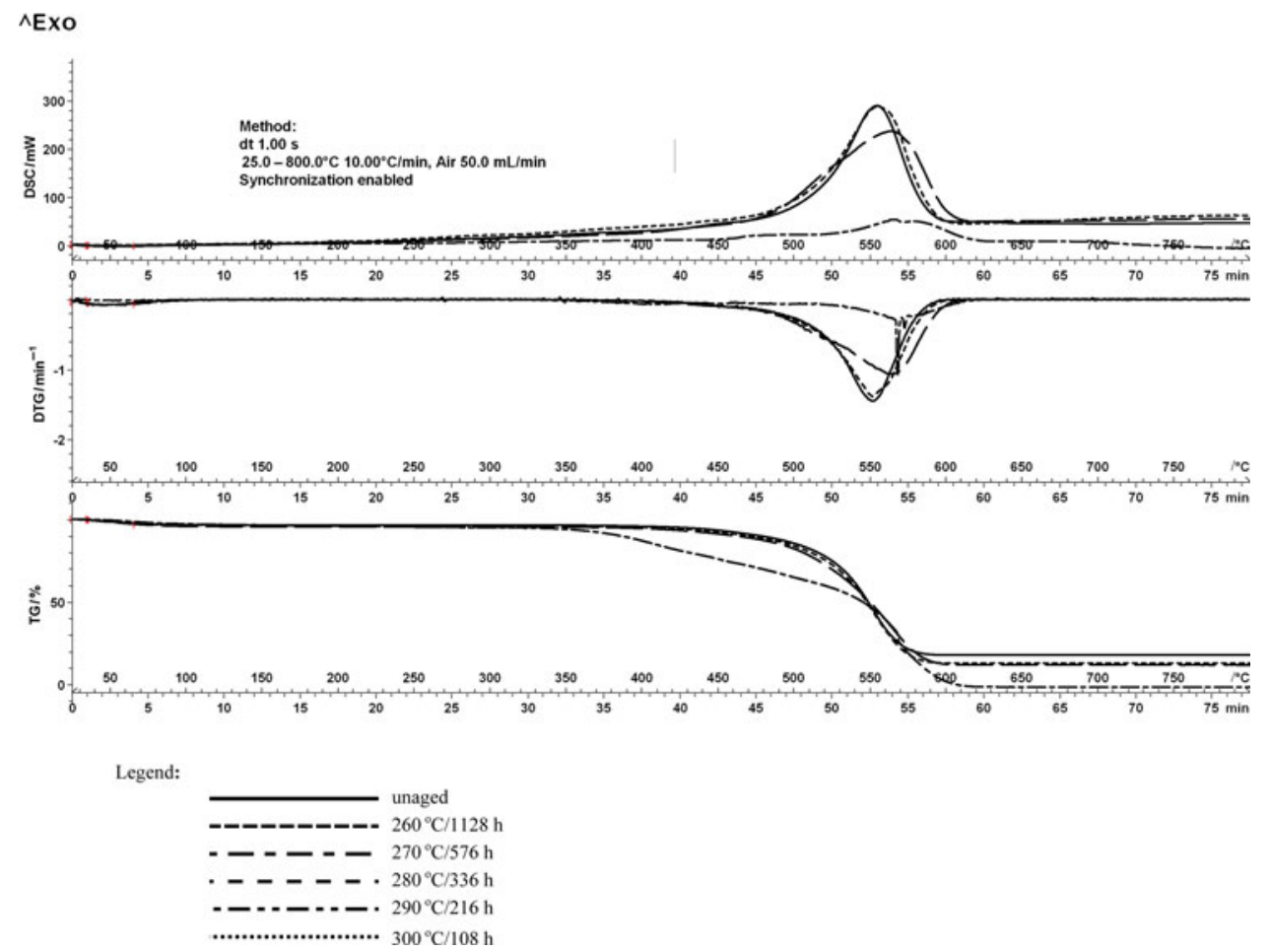


It could be expected that the thermograms would be the same, because the samples degradation reached the criterion specified in standard, but in fact they differed (Fig. 1). Only TG onset temperatures are almost the same for all samples. The main peaks of DSC and DTG shift to lower temperatures with the increase in ageing temperatures and their heights grow. In the air atmosphere the unaged enamel burn up at $800{ }^{\circ} \mathrm{C}$ and the TG curve did not show the mass residue. It is interested that the mass residue at $800{ }^{\circ} \mathrm{C}$ gradually increases after ageing, even to $27 \%$. Because ageing is performed on the samples of enamelled copper wire, thus copper ions can migrate into enamel [9]. Thus, the copper of conductor cannot only act as catalyst and accelerate degradation but can also go into enamel and decrease a breakdown voltage. The phenomena of the occurring of copper residue can be utilized as a sensitive indicator of an ageing stage.

The results of thermoanalytical testing of samples after different periods of continuous thermal ageing at $290{ }^{\circ} \mathrm{C}$ are shown in thermograms (Fig. 2). It can be noticed that nonisothermal behaviour of enamel has changed as a result of isothermal ageing. The DSC and DTG peaks shift to lower temperatures with a longer period of ageing. The scission reaction during thermo-oxidation causes that in pre-aged enamels degradation begins at lower temperatures.

The period of ageing do not influences to the onset TG (Fig. 2) while the temperature of $5 \%$ mass loss changes the most of all (Fig. 3). It increases by about $160{ }^{\circ} \mathrm{C}$ and therefore can be the sensitive indicator of stage of ageing. Table 2 shows the residue mass at $800{ }^{\circ} \mathrm{C}$ of samples aged at $290{ }^{\circ} \mathrm{C}$ that also much increases with longer period of ageing.

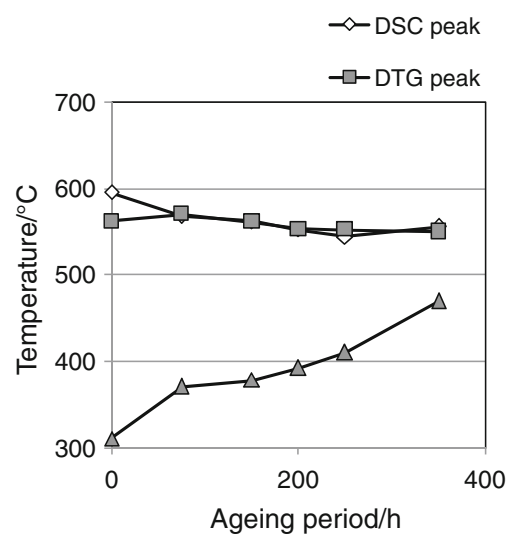

Fig. 3 The DSC and DTA peaks temperatures and 5\% loss of mass temperature versus period of ageing of samples aged at $290{ }^{\circ} \mathrm{C}$

Table 2 Residue mass at $800{ }^{\circ} \mathrm{C}$ of samples aged at 290 and $280{ }^{\circ} \mathrm{C}$ after various periods of ageing

Period of ageing at $290{ }^{\circ} \mathrm{C} / \mathrm{h}$ Mass residue at $800{ }^{\circ} \mathrm{C} / \%$

\begin{tabular}{lcc}
\cline { 2 - 3 } & Ageing at $290{ }^{\circ} \mathrm{C}$ & Ageing at $280{ }^{\circ} \mathrm{C}$ \\
\hline 0 & 0 & 0 \\
75 & 5 & 9 \\
150 & 12 & 11 \\
200 & 13 & 12 \\
250 & 13 & 12 \\
350 & 22 & 17 \\
\hline
\end{tabular}

Figure 4 presents the DSC and DTA peaks temperatures and $5 \%$ loss of mass temperature of samples aged at $280{ }^{\circ} \mathrm{C}$ for various period of ageing. At that lower ageing temperature it can be observed that both DSC and DTA
Fig. 2 TG, DTG and DSC curves of samples aged at $290{ }^{\circ} \mathrm{C}$ at various periods of ageing

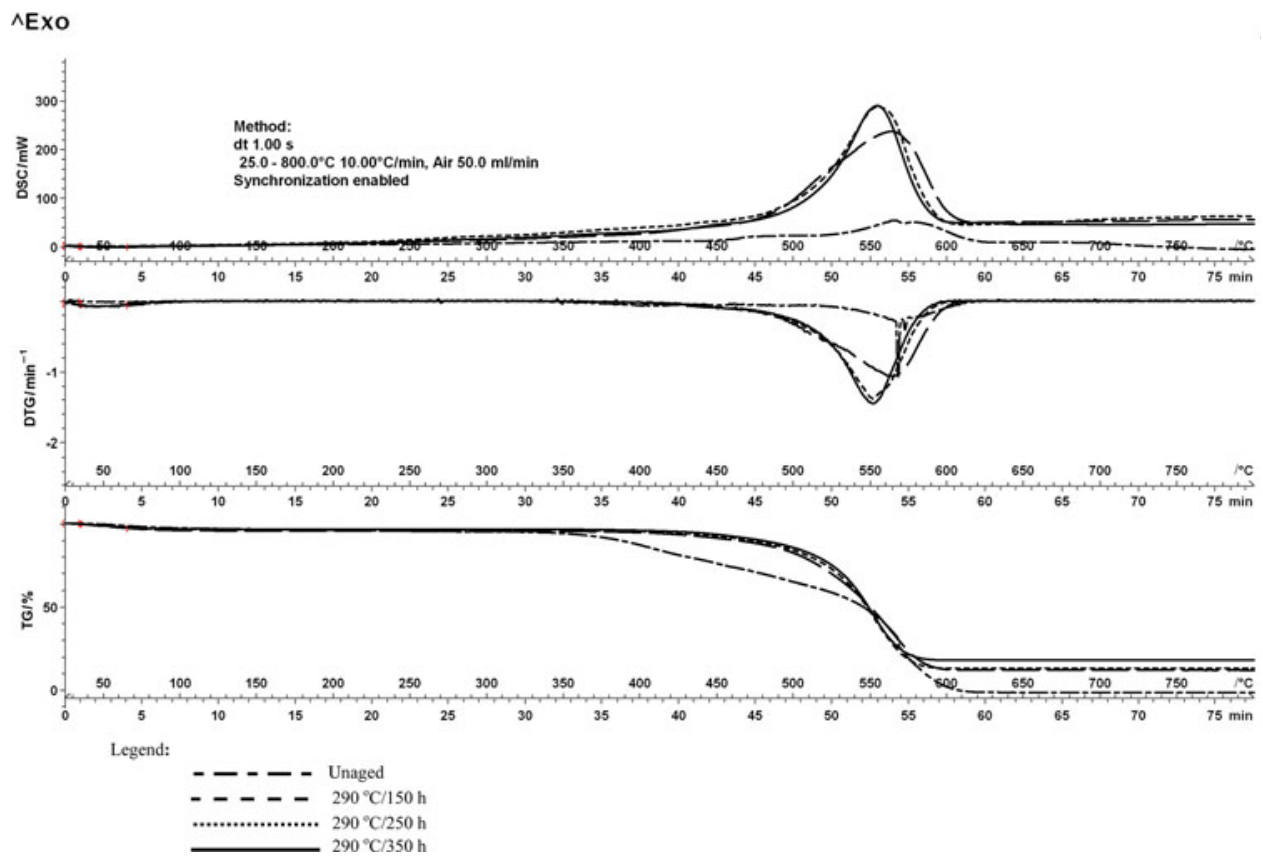




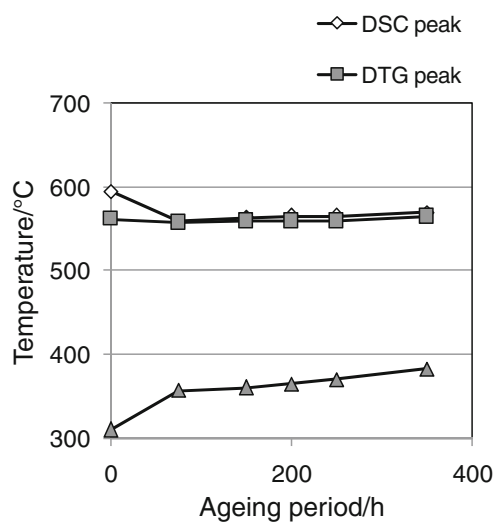

Fig. 4 The DSC and DTA peaks temperatures and 5\% loss of mass temperature versus period of ageing of samples aged at $280{ }^{\circ} \mathrm{C}$

peaks temperatures almost do not change with a longer time of exposure. However, the 5\% loss of mass temperature also increases but in a lesser degree than at ageing at $290 \mathrm{C}$ and the residue mass at $800{ }^{\circ} \mathrm{C}$ is also somewhat lesser (Table 2).

\section{Conclusions}

The results of thermoanalytical investigations of polyamide-imide-enamelled wire coating after thermal ageing have been presented. It was found that the thermograms TGA/DTG/DSC of samples that reach their lifetimes at the given temperature (i.e. at the same stage of degradation regarding the dielectric criterion) was not the same and depended on the ageing temperature.

With a longer ageing period the DSC and DTA curves of enamel shift to lower temperatures. However, the 5\% mass loss temperature seems to be the better indicator of stage of thermal degradation because it considerably grows during ageing. It was suggested that the observed phenomena of diffusion of copper ions into enamel during ageing can also be used for assessment of stage of ageing.

Acknowledgements This study was financed from the statute sources given by Polish Ministry of Science and Education (No. 500/ $8490 / 26 / 2009$ ).
Open Access This article is distributed under the terms of the Creative Commons Attribution Noncommercial License which permits any noncommercial use, distribution, and reproduction in any medium, provided the original author(s) and source are credited.

\section{References}

1. Minnick MG, EEIC.1999.826235, p. 337.

2. Aymonino F, Lebey T, Malec D, Petit C, Saint Michel J, Anton A, Gimenez A. IEEE Proceedings of the 7th ICSD'07, p. 130.

3. Li F, Xu X, Li Q, Li Y, Zhang H, Yu J, Cao A. Thermal degradation and their kinetics of biodegradable poly (butylene succinateco-butylene terephthate)s under nitrogen and air atmospheres. Polym Degrad Stab. 2006;91(8):1685-93.

4. Yingsuo Z, Yi B, Quixing X, Zhiping Z. Evaluation of thermal life for composite dielectrics. IEEE Electr Insul Mag. 1999;15(6): 12-9.

5. Saccani A, Motori A, Patuelli F. Thermal endurance evaluation of isotactic poly(propylene) based nanoanalytical methods. IEEE Trans Diel Electr Insul. 2007;14(3):689-95.

6. Manns D. Thermal endurance testing of rotor turn insulating materials. IEEE Trans Dielectr Electr Insul. 2006. doi:10.1109/ ELINSL.2006.1665248.

7. Aoyagi Y, Yamashita K, Doi Y. Thermal degradation of poly[ $(R)-3$-hydroxybutyrate], poly[E-caprolactone], and poly[ $(S)$ lactide]. Polym Degrad Stab. 2002;76(1):53-9.

8. Budrugeac P, Segal E. The application of the thermogravimetric analysis (tga) and of the differential thermal analysis (dta) for rapid thermal endurance testing of electrical insulating materials. Analele UniversităŃii din Bucuresti - Chimie, Anul XIV (serie nouă). 2005;I-II:241-6.http://gw-chimie.math.unibuc.ro/ anunivch/2005-2/AUBCh2005XIV2241246.pdf.

9. Araki C, Taguchi T. Thermal degradation of polyesterimide magnet wire. Conf Electr Insul Diel Phen. 1993. doi:10.1109/ CEIDP.1993.378919.

10. He W, Deng F, Liao G-X, Lin W, Jiang Y-Y, Jian X-G. Kinetics of thermal degradation of poly(aryl ether)s containing pthalazinone and life estimation. J Therm Anal Calorim. 2009;100:1055-62.

11. Afzal AB, Akhtar MJ, Svensson L-G. Thermal studies of DBSAdoped polyaniline/PVC blends by isothermal microcalorimetry. J Therm Anal Calorim. 2009;100:1017-25.

12. Li Y, Cheng Y, Ye Y, Shen R. Supplement on applicability of the Kissinger equation in thermal analysis. J Therm Anal Calorim. 2009. doi:10.1007/s10973-009-0612-4. 